\title{
Role of $\alpha$-Synuclein in Adult Neurogenesis and Neuronal Maturation in the Dentate Gyrus
}

\author{
Beate Winner, ${ }^{1,2 \star}$ Martin Regensburger, ${ }^{1,2,4,5 *}$ Sebastian Schreglmann, ${ }^{1,5}$ Leah Boyer, ${ }^{1,6}$ Iryna Prots, ${ }^{2}$ \\ Edward Rockenstein, ${ }^{7}$ Michael Mante, ${ }^{7}$ Chunmei Zhao, ${ }^{1}$ Jürgen Winkler, ${ }^{3}$ Eliezer Masliah, ${ }^{7}$ and Fred H. Gage ${ }^{1}$ \\ ${ }^{1}$ Laboratory of Genetics, The Salk Institute for Biological Studies, La Jolla, California 92037, ${ }^{2}$ Junior Research Group III and Federal Ministry of Education \\ and Research Group Neuroscience, Interdisciplinary Center for Clinical Research, Nikolaus-Fiebiger Center for Molecular Medicine, and Departments of \\ ${ }^{3}$ Molecular Neurology and ${ }^{4}$ Neurology, University Hospital Erlangen, Friedrich-Alexander-Universität Erlangen-Nürnberg, 91054 Erlangen, Germany, \\ ${ }^{5}$ University of Regensburg Medical School, 93053 Regensburg, Germany, and ${ }^{\circ}$ Biomedical Science Graduate Program, School of Medicine and \\ ${ }^{7}$ Departments of Neurosciences and Pathology, University of California, San Diego, La Jolla, California 92093
}

$\alpha$-Synuclein has been reported to be important in modulating brain plasticity and to be a key protein in neurodegenerative diseases, including Lewy body dementia (LBD). We investigated how $\alpha$-synuclein levels modulate adult neurogenesis and the development of dendritic arborization and spines in the dentate gyrus, in which new neurons are constantly added. In the human hippocampus, levels of endogenous $\alpha$-synuclein were increased in LBD, and the numbers of SOX2-positive cells were decreased. We investigated whether newly generated neurons were modulated by endogenous $\alpha$-synuclein, and we found increased adult neurogenesis in $\alpha / \beta$-synuclein knock-out mice. In contrast, overexpression of human wild-type $\alpha$-synuclein (WTS) decreased the survival and dendritic development of newborn neurons. Endogenous $\alpha$-synuclein expression levels increased the negative impact of WTS on dendrite development, suggesting a toxic effect of increasing amounts of $\alpha$-synuclein. To attempt a rescue of the dendritic phenotype, we administered rolipram to activate the cAMP response element-binding protein pathway, which led to a partial rescue of neurite development. The current work provides novel insights into the role of $\alpha$-synuclein in adult hippocampal neurogenesis.

\section{Introduction}

Cognitive decline is an important symptom in synucleinopathies, having a severe impact on the quality of life (Possin et al., 2008). Clinical and imaging studies have attributed cognitive decline in Parkinson's disease (PD) and Lewy body dementia (LBD) to impairments in hippocampal and cortical circuitries (Camicioli et al., 2003; McKeith et al., 2005; Apostolova et al., 2010; Molano et al., 2010; Pavese et al., 2010; Politis et al., 2010). Recently, a correlation between memory-encoding performance and hippocampal volume

\footnotetext{
Received May 18, 2012; revised Sept. 16, 2012; accepted Sept. 26, 2012.

Author contributions: B.W., M.R., E.M., and F.H.G. designed research; B.W., M.R., S.S., L.B., I.P., E.R., and M.M. performed research; L.B., C.Z., J.W., and E.M. contributed unpublished reagents/analytic tools; B.W., M.R., S.S., I.P., and C.Z. analyzed data; B.W. and F.H.G. wrote the paper.

This work was supported by grants from the Alexander von Humboldt Foundation, California Institute of Regenerative Medicine, the Michael J. Fox Foundation, the JPB Medical Foundation, the Lookout Fund, the Mather's Foundation, the Ellison Foundation, the Glenn Foundation, the Bavarian Ministry of Sciences, Research, and the Arts in the framework of the Bavarian Molecular Biosystems Reseach Network and ForNeuroCell, German Federal Ministry of Education and Research Grant 01GQ113, the Independent Research Program (School of Medicine, University of Regensburg), ELAN Program for supporting clinical research and teaching 11.08.19.1 (I.P.), and the Interdisciplinary Center for Clinical Research (University Hospital of Erlangen). We thank RobertAigner, Daniela Graef, Eunice Meija, Barbara Miller, and Chris Tse for excellent technical support and Christian Alzheimer and Tobias Huth for the use of the confocal microscope. We are grateful to Stefan Aigner, Nada Ben Abdallah, Armin Blesch, Zacharias Kohl, and Chichung D. Lieforhelpful comments on this manuscript and discussions and M. L. Gage for editing this manuscript.

${ }^{*}$ B.W. and M.R. contributed equally to this work.

Correspondence should be addressed to Dr. Beate Winner, Interdisciplinary Center for Clinical Research, NikolausFiebiger Center for Molecular Medicine, Friedrich-Alexander-Universität Erlangen-Nürnberg, Glücksstrasse 6, 91054 Erlangen, Germany. E-mail: beate.winner@med.uni-erlangen.de.

S. SchregImann's present address: University Hospital Zurich, Clinic for Neurology, 8091 Zürich, Switzerland.

DOI:10.1523/JNEUROSCI.2723-12.2012

Copyright $\odot 2012$ the authors $\quad 0270-6474 / 12 / 3216906-11 \$ 15.00 / 0$
}

(using voxel-based morphometry) in nondemented PD patients was reported (Weintraub et al., 2011). In addition, using diffusion tensor imaging techniques, Carlesimo et al. (2012) showed that microstructural hippocampal alterations in nondemented PD patients were related to decreased declarative memory. The pathological hallmark of PD and LBD is the aggregation of $\alpha$-synuclein as Lewy bodies and Lewy neurites (Spillantini et al., 1997; Baba et al., 1998). As proposed by Braak et al. (2003), Lewy body formation is observed in different brain regions as the disease progresses, including the limbic system in many cases. Although a physiological presynaptic role for $\alpha$-synuclein is well established, dysfunction of neurites is presently less understood (Kramer and Schulz-Schaeffer, 2007).

The integration and connectivity of new neurons play important roles in adult neurogenesis in the hippocampus. Adult neurogenesis persists throughout life in the hippocampal dentate gyrus (DG) (Altman and Das, 1965) in all mammals, including humans (Eriksson et al., 1998; Knoth et al., 2010). In the DG, adult neurogenesis contributes to hippocampus-dependent learning and memory (i.e., in spatial pattern separation, as shown in low-dose $\mathrm{x}$-irradiation models; Clelland et al., 2009). Studies in various animals and humans affected by neurodegenerative diseases have convincingly shown that hippocampal neurogenesis is modulated and, under many circumstances, decreased, indicating a limited cellular plasticity (for review, see Winner et al., 2011). The clinical significance of human hippocampal adult neurogenesis in neurodegenerative diseases is still under debate.

The role of $\alpha$-synuclein in adult neurogenesis has been extensively studied in the subventricular zone/olfactory bulb system, 
Table 1. Summary of clinico-pathological characteristics of human cases

\begin{tabular}{llllllllcc}
\hline Group & $n$ & Age (years) & Postmortem (hours) & Gender (males/females) & Brain weight (g) & Education (years) & Duration (years) & Blessed score (range) & Lewy bodies \\
\hline Control & 6 & $86.0 \pm 10$ & $12.8 \pm 7.2$ & $3 / 3$ & $1177 \pm 120$ & $13.3 \pm 3.3$ & 0 & $0-3$ & $0-1$ \\
DLB & 6 & $81.0 \pm 9.1$ & $9.5 \pm 3.1$ & $5 / 1$ & $1368 \pm 192$ & $16.2 \pm 2.7$ & $8.5 \pm 3.0$ & $10-27$ & $10-39$ \\
\hline
\end{tabular}

but less is known about its function in the generation of new neurons in the DG. Impaired neurogenesis in the DG was reported in brains from PD patients with dementia and in murine models of synucleinopathies (Höglinger et al., 2004; Winner et al., 2004). We chose a selective and complementary approach to understand the role of $\alpha$-synuclein in regulating adult hippocampal neurogenesis in PD and LBD. In the work presented here, we examined the endogenous expression of $\alpha$-synuclein in mouse and human hippocampus with LBD. We observed an increase in new neurons in the DG in an $\alpha / \beta$-synuclein knock-out background. In addition, we found that $\alpha$-synuclein is associated with dendrite and spine development, depending on the expression level. We show here that $\alpha$-synuclein regulates dendritic maturation of newly generated neurons.

\section{Materials and Methods}

Human specimen processing, neuropathological evaluation, and criteria for disease stage. A total of 12 human cases $(n=6$ nondemented controls; $n=6 \mathrm{LBD}$ ) was included in the present study (Table 1 ). Human brain tissue was obtained at autopsy from patients studied at the Alzheimer Disease Research Center/University of California, San Diego. The last neurobehavioral evaluation was performed within the 12 months before death and included Blessed score (range of $0-28 ; 0-4$, normal cognition; $\geq 10$, impairment consistent with dementia). Autopsies were performed within $24 \mathrm{~h}$ of death (Table 1, postmortem hours). Brains were processed and evaluated according to standard methods. At autopsy, brains were divided sagittally; the left hemibrain was fixed in Formalin or $4 \%$ paraformaldehyde for subsequent neuropathological and immunohistochemical analysis.

Animals. All animal procedures were performed in accordance with the protocols approved by the animal care use committees of the Salk Institute for Biological Studies and University of California, San Diego following National Institutes of Health guidelines for the humane treatment of animals. All mice were kept in a normal $12 \mathrm{~h}$ light/dark cycle and had access to food and water ad libitum. Mice overexpressing human wild-type $\alpha$-synuclein (WTS) under the PDGF promoter were compared with non-transgenic (Tg) littermate controls (NTG). The PDGF WTS group was the WTS high expresser line D; the genetic background was DBA (Masliah et al., 2000; Rockenstein et al., 2002).

$\alpha / \beta$-Synuclein knock-out mice lacking genes for $\alpha$ - and $\beta$-synuclein (SNCA, SNCB) were obtained from The Jackson Laboratory and have been characterized extensively (Chandra et al., 2004). As controls, we used B6129SF2/J (stock \#101045), which are F2 hybrids of C57BL/6 and 129S1/SvImJ mice, because according to The Jackson Laboratory (personal communication), the background of these mice best approximates the mixed background of the B6;129-Snca/tm1Sud $/ \mathrm{Sncb} / \mathrm{tm} 1.1 \mathrm{Sud} / \mathrm{J}$ (stock \#006390) mice. Acknowledging that the levels of adult neurogenesis can vary between C57BL/6 and 129S1/SvImJ, we added another group of pure C57BL/6 mice to our study.

Analysis of neurogenesis. Analysis of neurogenesis, including BrdU injection, tissue preparation, and immunostaining, was performed as described previously (Winner et al., 2004). A daily intraperitoneal BrdU injection $(50 \mathrm{mg} / \mathrm{kg}$ ) was given for $5 \mathrm{~d}$. The animals were killed after 1 month. The paradigms are indicated with the respective figures.

Retrovirus-mediated labeling and analysis of new neurons in the mouse hippocampus. We used a Moloney murine leukemia retrovirus that has been described previously (Zhao et al., 2006) and was a gift from Drs. Gerald Pao and Inder Verma (Salk Institute, La Jolla, CA). In brief, CAG-GFP uses the backbone of pCLNCXv.2. The expression of enhanced green fluorescent protein (GFP) is driven by the compound promoter CAG. The concentrated viral solution $\left(10^{8} \mathrm{pfu} / \mathrm{ml}\right)$ was prepared with human embryonic kidney 293T packaging cells. To perform a detailed analysis of dendritic arborization and spines, adult female PDGFWTS mice and NTG controls, all aged 4 months ( $n=8$ per group), were stereotactically injected with $1.5 \mu \mathrm{l}$ of retrovirus into the right DG at a flow rate of $0.25 \mu \mathrm{l} / \mathrm{min}$ at the following coordinates: anteroposterior, 2 $\mathrm{mm}$; mediolateral, $+1.6 \mathrm{~mm}$ from bregma; dorsoventral, $-2.3 \mathrm{~mm}$ from skull.

CAG-WTS-GFP retrovirus was used to selectively study the effect of WTS in newly generated neurons. WTS CDNA was amplified by PCR (nucleotides 53-475; GenBank accession number L08850). To generate the human WTS-GFP fusion construct, WTS cDNA was cloned without a stop codon and ligated to the $5^{\prime}$ end of GFP (nucleotides 826-1545; GenBank accession number U43284), cloned into a Bluescript cloning vector (Invitrogen) and sequenced for accuracy. In this construct, GFP was thus fused to the C-terminal site of WTS. The 5' WTS-GFP 3 ' cDNA fragment was cloned into the CAG vector, concentrated, and stereotactically injected as described above. To compare CAG-GFP and CAGWTS-GFP, naive female C57BL/6 mice were injected ( $n=7,7$ weeks old). For the analysis of CAG-GFP versus CAG-WTS-GFP in $\alpha / \beta$ synuclein knock-out mice, $\alpha / \beta$-synuclein knock-out mice and controls were injected ( $n=7,7$ weeks old). One or 3 months after the injection, the animals were killed and further processed for immunostainings as described previously (Winner et al., 2004).

Rolipram treatment. Animals in the rolipram experiment received rolipram $(1.25 \mathrm{mg} / \mathrm{kg}$; Sigma; dissolved in sterile saline and freshly prepared daily) or sterile saline by intraperitoneal injection once daily at the age of 7 weeks until perfusion $35 \mathrm{~d}$ later. Five days after the first injection, CAG-GFP or CAG-WTS-GFP retrovirus was infused into the right hippocampus as described above. In addition, BrdU was administered once daily for $5 \mathrm{~d}$ starting on the day of stereotactical infusion as described above, and animals were perfused 1 month later ( $n=4$ per group).

Antibodies and immunochemicals for mouse tissue. Primary antibodies and final dilutions for mouse brains included the following: rat $\alpha$-BrdU at 1:500 (Oxford Biotechnology), mouse $\alpha$-NeuN at 1:500, mouse $\alpha$-Sox2 (sex-determining region Y-box 2; marker of neural stem cells), rabbit $\alpha$-VAMP2 (Millipore Bioscience Research Reagents), goat $\alpha$-doublecortin (DCX) at 1:500 (Santa Cruz Biotechnology), rat $\alpha$-human $\alpha$-synuclein 15G7 at 1:500 (Zymed), chicken $\alpha$-GFP at 1:250 (Invitrogen), rabbit $\alpha$-proliferating cell nuclear antigen (PCNA) at 1:500 (Abcam), and rabbit $\alpha$-cleaved Caspase-3 at 1:250 (Cell Signaling Technology). Secondary antibodies for immunofluorescence included the following: donkey $\alpha$-goat, $\alpha$-mouse, $\alpha$-rabbit, $\alpha$-chicken, or $\alpha$-rat conjugated with fluorescein (FITC), rhodamine X, or Cy5 at 1:500 (Jackson ImmunoResearch). To control the specificity of antibody staining, we performed the following negative controls: (1) leaving primary antibody incubation out, (2) preincubation with blocking peptide, (3) isotype controls, and (4) comparison with knock-out animals.

Immunohistochemical analysis of human tissue. For analysis of levels of $\alpha$-synuclein and SOX2 in the hippocampus of LBD patients and controls, systematically sampled brain sections were immunolabeled with the antibodies against $\alpha$-synuclein at 1:1000 (rabbit $\alpha$-synuclein, 5038P; Millipore). SOX2 antibodies at 1:500 (mouse monoclonal; Sigma-Aldrich) were detected with the Tyramide Signal Amplification-Direct (Red) system (PerkinElmer Life and Analytical Sciences). A subset of sections immunolabeled with the SOX2 antibody was colabeled with the antibody against $\alpha$-synuclein detected with FITC-conjugated secondary antibodies (1:75; Vector Laboratories).

Human sections were mounted under glass coverslips with ProLong Gold antifade reagent with DAPI (Invitrogen) and imaged with a Carl Zeiss $63 \times$ [numerical aperture (NA) 1.4] objective on an Axiovert 35 microscope (Carl Zeiss) with an attached MRC1024 laser scanning confocal microscope system (Bio-Rad; Masliah et al., 2000). All sections were 
A control

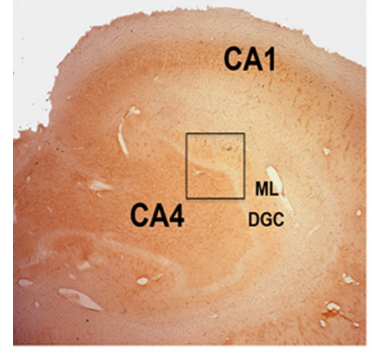

LBD

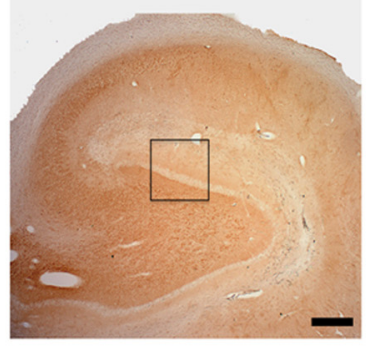

$\alpha$-syn

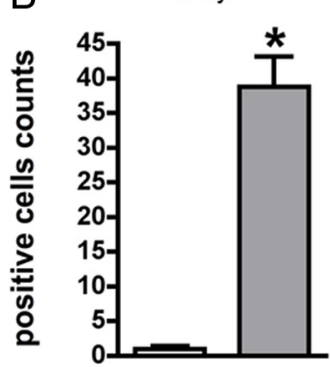

C

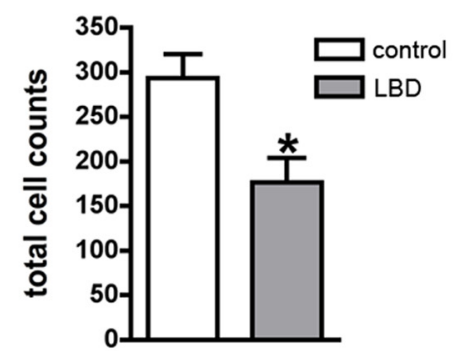

D
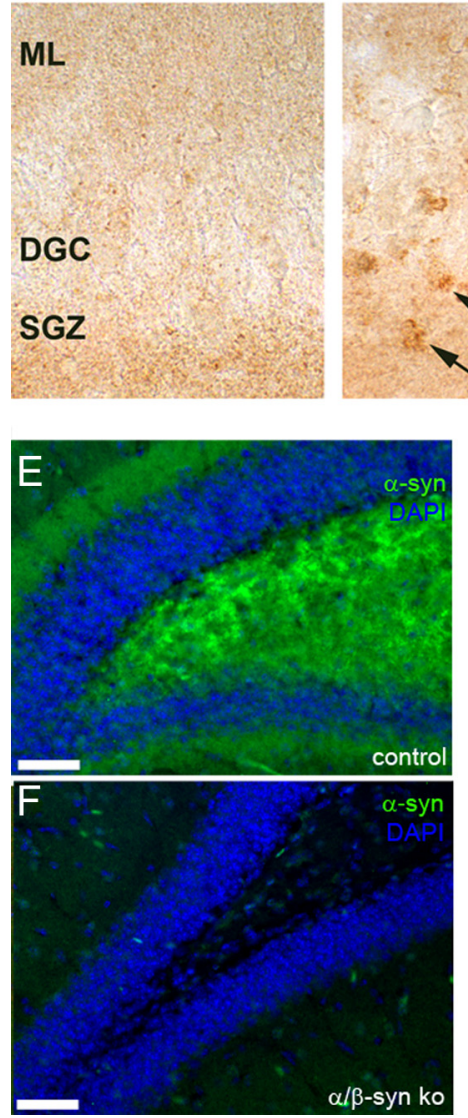

LBD
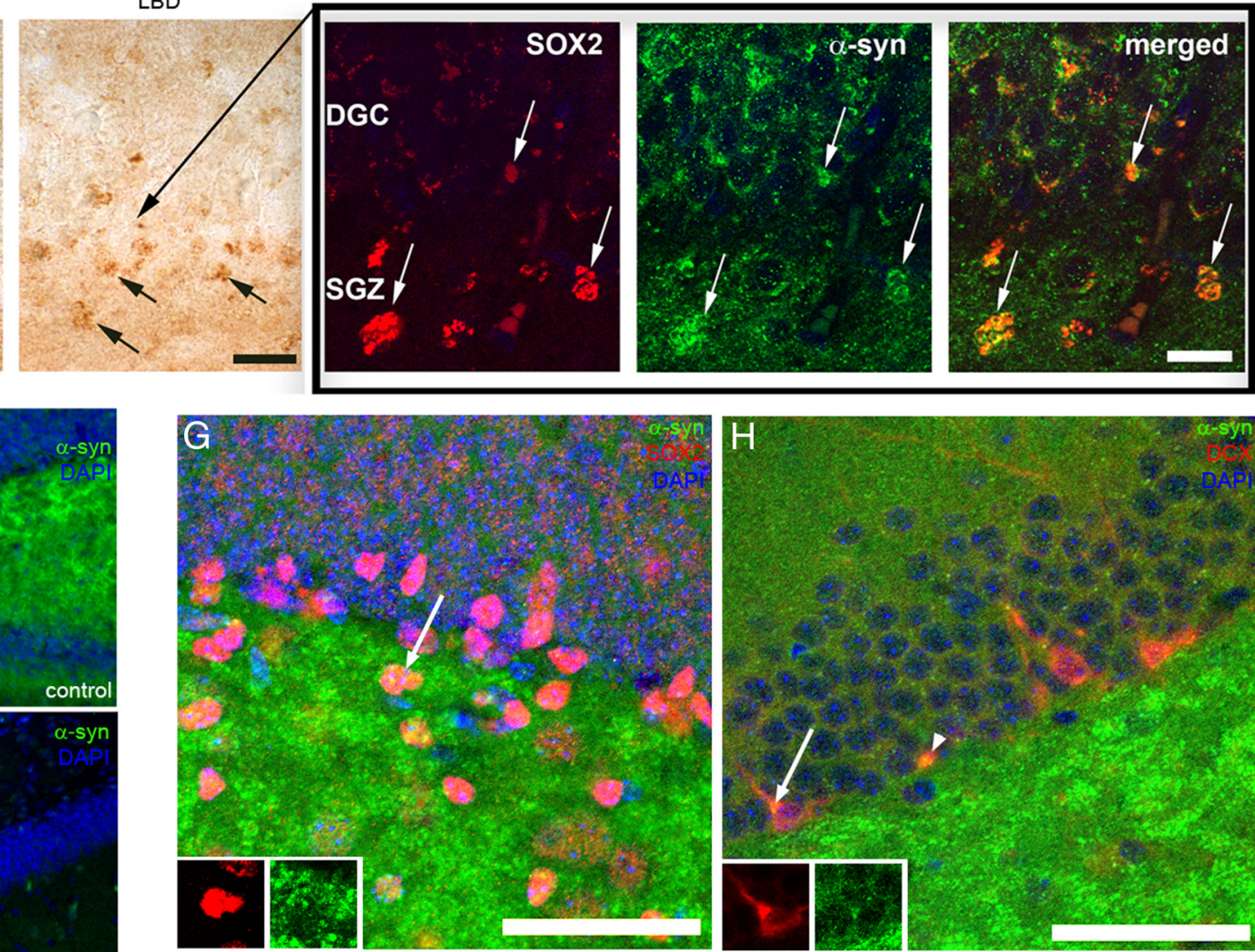

Figure 1. Endogenous expression of $\alpha$-synuclein in human and mouse DG. $\alpha$-Synuclein ( $\alpha$-syn) staining in the brains of LBD patients and controls shows expression in the CA regions and DGC $(\boldsymbol{A})$ and, less extensively, in the molecular layer (ML; black boxes further magnified in $\boldsymbol{D})$. The number of $\alpha$-synuclein ${ }^{+}$cells in the DG is significantly increased in the brains of $L B D$ patients $(\boldsymbol{B})$. SOX2 ${ }^{+}$cells are decreased in the brains of LBD patients (C). SOX2 and $\alpha$-synuclein colabel in human LBD brains ( $\boldsymbol{D}$; arrows indicate $\alpha$-synuclein and SOX2 double-labeled cells). In murine brains, $\alpha$-synuclein is strongly expressed in the hilus and, to a lesser extent, the DG in control mice $(\boldsymbol{E})$ but is absent in $\alpha / \beta$-knock-out $(\mathrm{ko})$ mice $(\boldsymbol{F})$. Endogenous $\alpha$-synuclein colabels with SOX2 and DCX in mouse brain $\left(\boldsymbol{G}, \boldsymbol{H}\right.$ indicate examples of a double-labeled cell). $\boldsymbol{H}$, Arrows indicate coexpression with $\alpha$-synuclein: arrow shows a DCX+ ${ }^{+}$cell with a neurite reaching into the $D G$, and arrowhead shows a tangential DCX ${ }^{+}$cell. Scale bars: $\boldsymbol{A}, 500 \mu \mathrm{m} ; \boldsymbol{D}, 30 \mu \mathrm{m} ; \boldsymbol{E}-\boldsymbol{H}, 50 \mu \mathrm{m} .{ }^{*} p<0.05$ in $\boldsymbol{B}$ and $\boldsymbol{D}$.

processed simultaneously under the same conditions and the experiments were performed twice to assess reproducibility. To confirm the specificity of primary antibodies, control experiments were performed in which sections were incubated overnight in the absence of primary antibody or of primary antibody preincubated with blocking peptide. For all human immunolabeling studies, assessment of levels of immunoreactivity was performed using the Image-Pro Plus program (Media Cybernetics). For each case, three systematically sampled sections (10 images per section) were analyzed to estimate the average number of immunolabeled cells per unit area (square millimeters).

Immunofluorescence. Free-floating sections were washed in TBS and then incubated in TBS $/ 0.25 \%$ Triton X-100/3\% donkey serum for 30 min, followed by incubation with primary antibodies in TBS/donkey serum overnight at $4^{\circ} \mathrm{C}$. Afterwards, primary antibodies were applied in $\mathrm{TBS} /$ donkey serum for $48 \mathrm{~h}$ at $4^{\circ} \mathrm{C}$, followed by incubation with second- ary antibodies as described above. After several washes in TBS, sections were mounted on gelatin-coated glass slides and coverslipped using Prolong (Invitrogen). For detection of BrdU-labeled nuclei, the following DNA denaturation steps preceded the incubation with antiBrdU antibody: $2 \mathrm{~h}$ incubation in $50 \%$ formamide $/ 2 \times$ SSC $(2 \times$ SSC: $0.3 \mathrm{M} \mathrm{NaCl}$ and $0.03 \mathrm{M}$ sodium citrate) at $65^{\circ} \mathrm{C}, 5 \mathrm{~min}$ rinse in $2 \times \mathrm{SSC}$, $30 \mathrm{~min}$ incubation in $2 \mathrm{M} \mathrm{HCl}$ at $37^{\circ} \mathrm{C}$, and $10 \mathrm{~min}$ rinse in $0.1 \mathrm{M}$ boric acid, $\mathrm{pH} 8.5$.

Counting procedures. For quantification, a systematic, random counting procedure, similar to the optical dissector (Gundersen et al., 1988), was used as described by Williams and Rakic (1988).

Every sixth section (200 $\mu \mathrm{m}$ interval) was selected from each animal and processed for immunohistochemistry. Sections were analyzed for BrdU-positive $\left(\mathrm{BrdU}^{+}\right)$cells in the hippocampal DG, which were exhaustively counted on each section under exclusion of the 
A

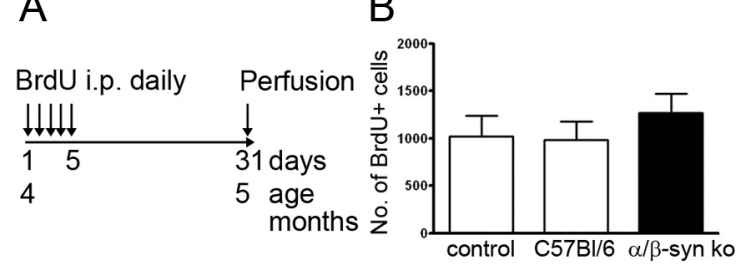

E
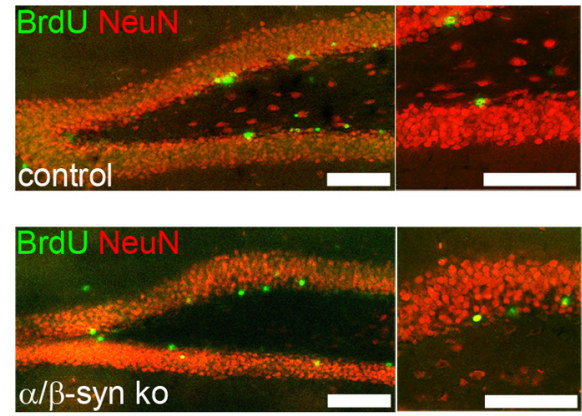

C

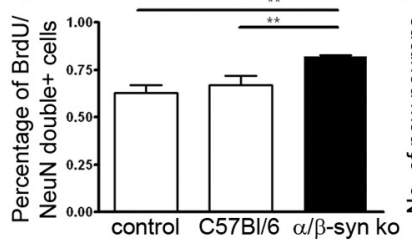

$\mathrm{F}$

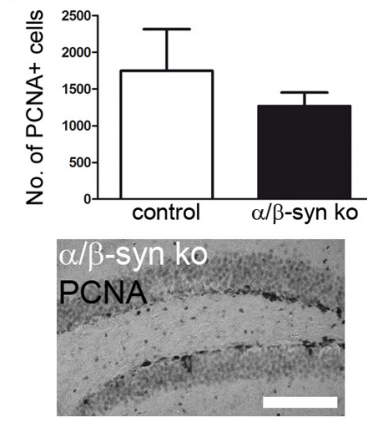

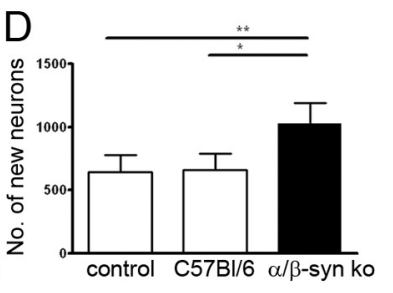

G

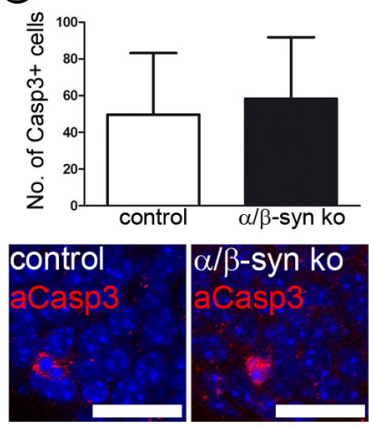

Figure 2. Neurogenesis in $\alpha / \beta$-synuclein knock-out mice. $A$, Adult neurogenesis was quantified in $\alpha / \beta$-synuclein knock-out mice $(\alpha / \beta$-syn ko) and two control groups using a 1 month BrdU survival paradigm ( $n=7$ animals per group). $\boldsymbol{B}$, Survival of newly generated cells (number of $B r d U^{+}$cells) was unchanged between groups. However, there was a significant increase in relative $(\boldsymbol{C})$ and absolute $(\boldsymbol{D})$ numbers of newborn neurons in $\alpha / \beta$-synuclein knock-out mice. Representative micrographs of the $D G$ of littermate control and in $\alpha / \beta$-synuclein knock-out mice $(\boldsymbol{E})$. Proliferation (number of PCNA ${ }^{+}$cells; $\boldsymbol{F}$ ) and cell death (number of activated Caspase- $3^{+}$cells) in $\boldsymbol{G}$ were not significantly different. Scale bars: $\boldsymbol{E}, 50 \mu \mathrm{m} ; \boldsymbol{F}, 200 \mu \mathrm{m} ; \boldsymbol{G}, 20 \mu \mathrm{m} .{ }^{*} p<0.05,{ }^{* *} p<0.01$.
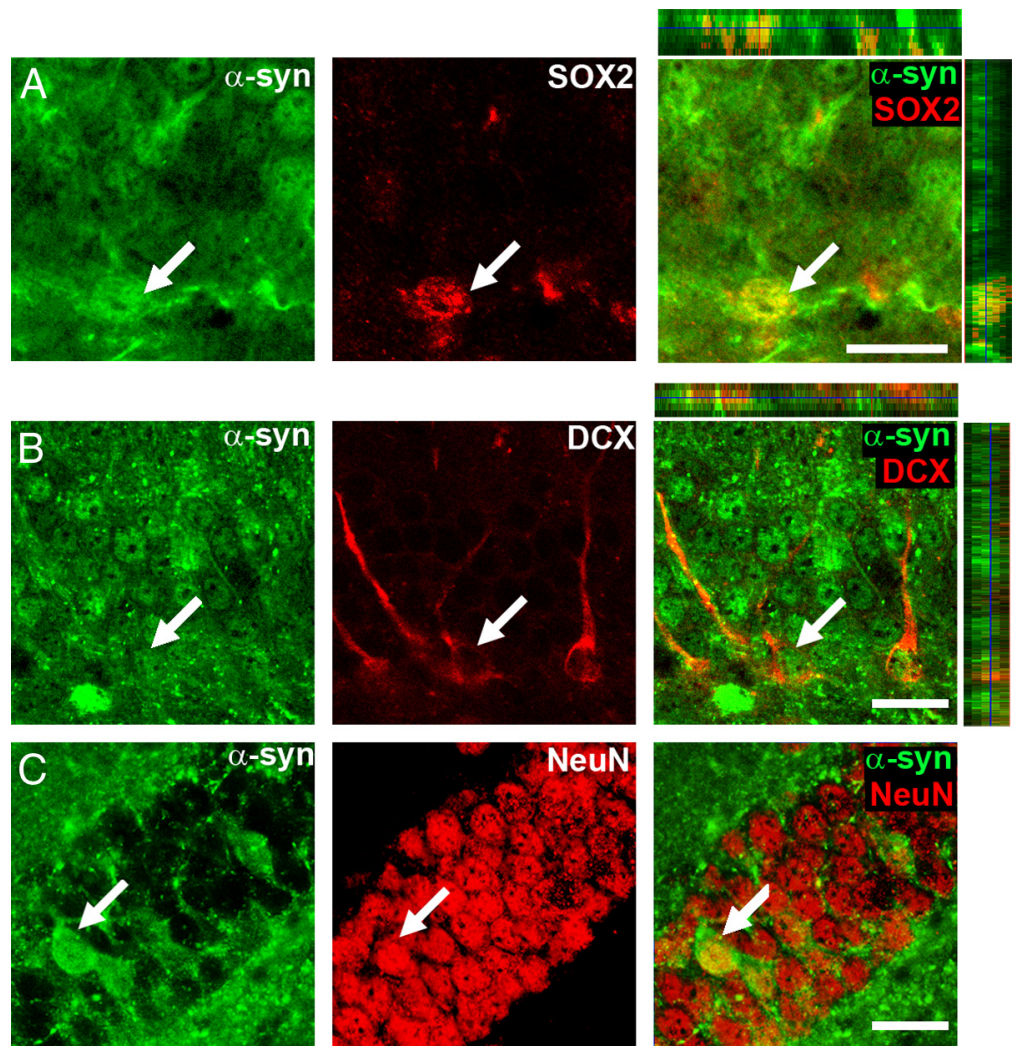

Figure 3. Colocalization of $\alpha$-synuclein ( $\alpha$-syn) in PDGF WTS mice. Colocalization analysis of human WTS with markers at different stages of neuroblast development in the DG reveals temporal expression patterns of WTS during the generation of new neurons in PDGF WTS mice. WTS is expressed at all adult neural progenitor stages, colabeling with SOX2 $(\boldsymbol{A}), \mathrm{DCX}(\boldsymbol{B})$, and $\operatorname{NeuN}(\boldsymbol{C})$. Arrows indicate examples of double-labeled cells in $\boldsymbol{A}$-C. Scale bars, $25 \mu \mathrm{m}$.

uppermost focal plane. The reference volume was determined by tracing the areas using a semiautomatic stereology system (Stereoinvestigator; MicroBrightField).

To determine the frequency of neuronal differentiation of newborn cells, a series of every sixth section ( $150 \mu \mathrm{m}$ interval) was examined using a confocal laser microscope (Leica TCS-NT) equipped with a $40 \times$ Plan Apochromat oil objective (NA 1.25) and a pinhole setting that corresponded to a focal plane of $2 \mu \mathrm{m}$ or less. On average, $50 \mathrm{BrdU}^{+}$cells were analyzed in the DG of each animal. Cells were randomly selected and analyzed by moving through the $z$-axis of each cell to exclude false-positive double labeling attributable to the overlay of signals from different cells (Kuhn et al., 1996). Colabeling was analyzed sequentially at each wavelength and in the $z$-axis to ensure that the fluorophores were present in the identical focal plane.

Dendritic growth and spine density of $\mathrm{GFP}^{+}$ neurons. These analyses were conducted as described previously (Zhao et al., 2006). Briefly, for dendrite analysis, $z$-series at $1.5 \mu \mathrm{m}$ intervals were acquired with a Bio-Rad Radiance 2100 confocal system from sections stained with the GFP antibody. Two-dimensional maximum intensity projections were created with Confocal Assistance Program (Bio-Rad), and files were imported into IGL Trace to measure total length of the dendritic tree within the section. The number of branching points was counted manually from the same images. At least 15 cells from three mice were analyzed for each data point. For spine density analysis and mushroom spine classification, close-up images of $\mathrm{GFP}^{+}$dendritic processes were acquired in the outer molecular layer at $0.5 \mu \mathrm{m}$ intervals with a $60 \times$ oil lens (NA 1.4; Nikon) and a digital zoom of 5 . For spine analyses, sections were not stained to preserve the GFP signal. The Bio-Rad image files were subjected to five iterations of deconvolution with AutoDeblur (AutoQuant). Maximum intensity projections of $z$-series were created with the Confocal Assistance Program, and files were imported into IGL Trace. The length of each dendritic segment was determined by tracing the center of the dendritic shaft, and the number of spines was 
A
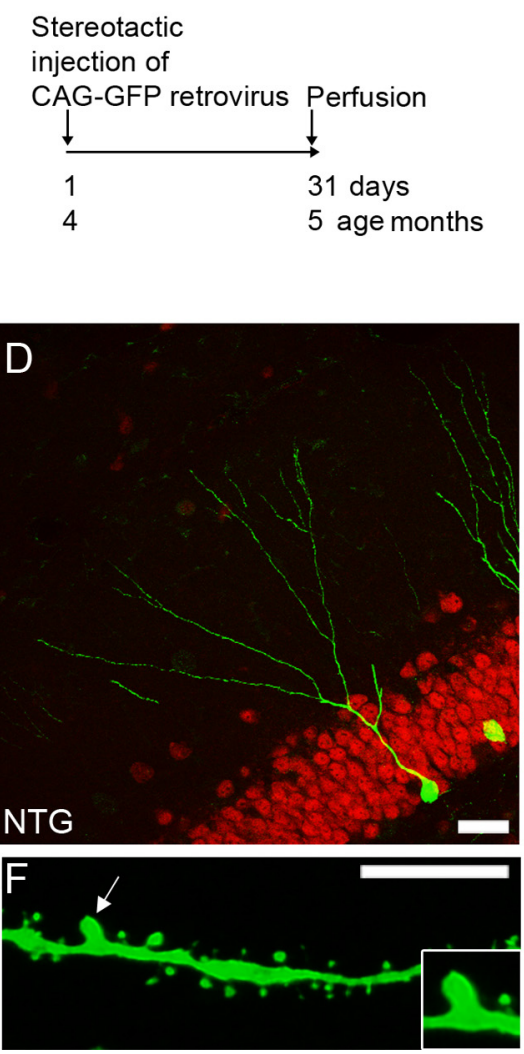

$\mathrm{B}$
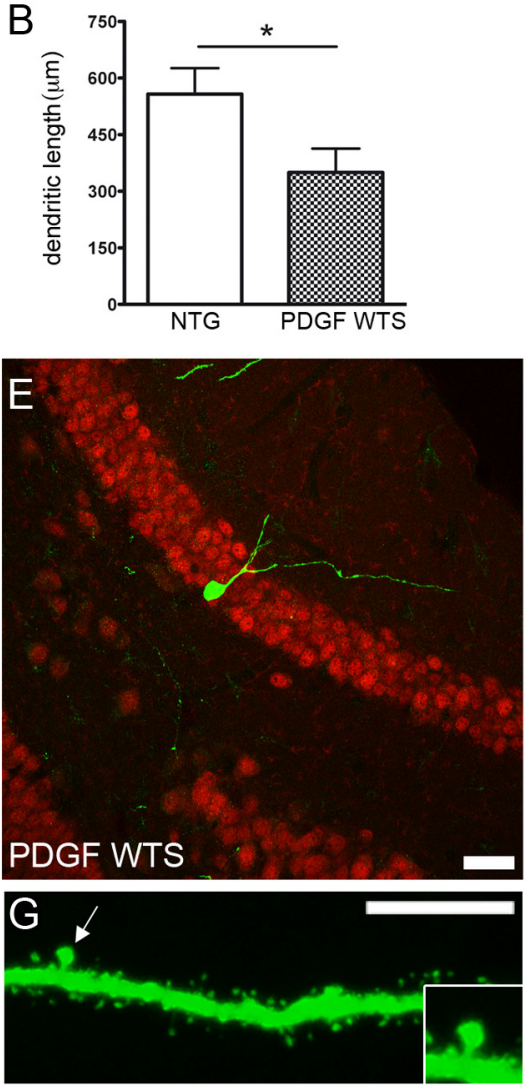
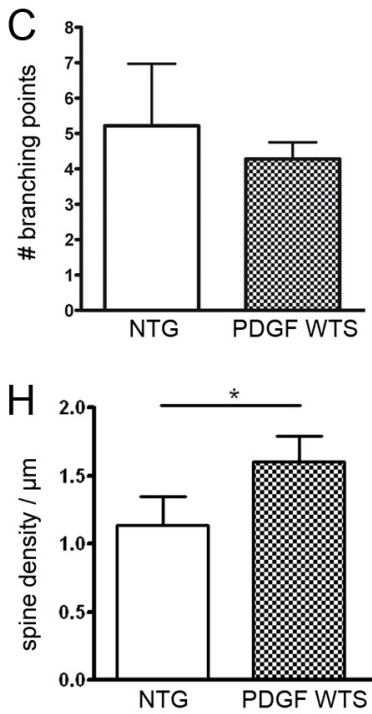

I

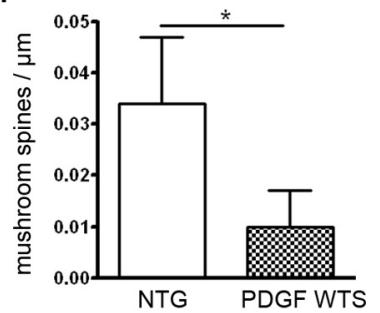

Figure 4. Compromised dendritic morphology in $\alpha$-synuclein Tg animals. $\boldsymbol{A}$, Paradigm: (AG-GFP retrovirus was stereotactically injected into the DG of PDGFWTS and NTG ( $n=8$ animals per group). $\boldsymbol{B}$, Total dendritic length of newly generated neurons was significantly decreased in PDGF WTS mice. $C$, No significant differences were detected in the number of dendritic branching points. Representative images of dendrites $(\boldsymbol{D}, \boldsymbol{E})$ and spines $(\boldsymbol{F}, \boldsymbol{G}$; arrows in $\boldsymbol{F}$ and $\boldsymbol{G}$ and insets indicate mushroom spine example) analyzed from the respective groups. The analysis of dendritic spines ( $\boldsymbol{H})$ revealed an increase in spine density of newly generated neurons in PDGFWTS animals. I, Density of mushroom spines was significantly decreased in PDGFWTS mice. Scale bars: $\boldsymbol{D}, \boldsymbol{E}, 25 \mu \mathrm{m} ; \boldsymbol{F}, \boldsymbol{G}, 10 \mu \mathrm{m}$. ${ }^{*} \boldsymbol{P}<0.05$.

counted manually from the two-dimensional projections. Spine density was calculated by dividing the total number of spines by the length of the dendritic segment. For classification of mushroom spines, major and minor axes of each spine head were identified, and the size of the spine head was represented by the estimated surface area with the function $0.25 \times \pi \times$ $D_{\text {major }} \times D_{\text {minor }}$ A spine was considered to be of mushroom type if the average estimated area from three measurements was $>0.4 \mu \mathrm{m}^{2}$ (Zhao et al., 2006). At least 40 dendritic segments from three to four mice were analyzed for each data point. Confocal imaging and data quantification were performed blinded to the experimental conditions.

Statistical analyses. The data were expressed as mean \pm SD values and were tested by an unpaired, two-sided $t$ test for significant differences. Dendrite and spine analyses were compared by one-way ANOVA, and analyses in the rolipram experiment were compared by two-way ANOVA with the variables treatment and virus, both followed by Bonferroni's multiple comparison post hoc tests. Data were analyzed in Prism (GraphPad Software), and the significance level was $p<0.05$.

\section{Results}

Endogenous expression of $\alpha$-synuclein in human and mouse We compared $\alpha$-synuclein expression in the hippocampi of LBD patients and controls. $\alpha$-Synuclein ${ }^{+}$cells were rarely found in controls (Fig. $1 A, B$ ). In LBD patients, $\alpha$-synuclein was expressed in the deep granule cell layer (DGC), subgranular zone (SGZ), and hilus (Fig. 1A) of the hippocampus, and the number of $\alpha$-synuclein ${ }^{+}$cells was increased in the SGZ of LBD patients (Fig. $1 B$, Table 1$)$. We found a decrease in SOX $2^{+}$cells in the SGZ of LBD patients (Fig. 1C). SOX2 and $\alpha$-synuclein colabeled in human LBD brains (Fig. 1D). In the DG of murine control mice, endogenous $\alpha$-synuclein was expressed mainly in the hilus and at low levels in the SGZ and DGC (Fig. 1E). $\alpha$-Synuclein was absent in the hippocampus of $\alpha / \beta$-synuclein knock-out mice (Fig. $1 F$ ). Endogenous $\alpha$-synuclein colabeled with SOX2 in the SGZ and DCX in the DG in mouse brain (Fig. $1 G, H$ ).

\section{Increased adult neurogenesis in $\boldsymbol{\alpha} / \boldsymbol{\beta}$-synuclein} knock-out mice

Because $\alpha$-synuclein was endogenously expressed in the murine and human DG, we asked whether the number of newly generated neurons was also modulated by endogenous $\alpha$-synuclein. We used $\alpha / \beta$-synuclein knock-out mice (Chandra et al., 2004) that were killed 1 month after BrdU injection (Fig. 2A). There was no difference in survival of $\mathrm{BrdU}^{+}$newly generated cells (Fig. $2 B)$, but there was a significant increase in neuronal differentiation (percentage of BrdU/NeuN double-positive cells) in $\alpha / \beta$ synuclein knock-outs (Fig. $2 C, E$ ), which led to a significant increase in new neurons (as calculated by the ratio of $\operatorname{BrdU} \times$ $\% \mathrm{BrdU} / \mathrm{NeuN}^{+}$cells; Fig. $2 \mathrm{D}$ ). A similar increase in neuronal differentiation in $\alpha / \beta$-synuclein knock-outs was observed when compared with C57BL/6 mice (Fig. 2B-D). The numbers of $\mathrm{PCNA}^{+}$cells (Fig. $2 F$ ) and activated Caspase- $3^{+}$cells (Fig. $2 G$ ) were not altered in $\alpha / \beta$-synuclein knock-outs.

Temporal expression pattern of WTS Tg mice resembles the endogenous expression

To further investigate the role of $\alpha$-synuclein on newly generated neurons, we investigated colocalization of WTS with markers of specific stages of neuroblast development. In PDGF WTS mice, 
A
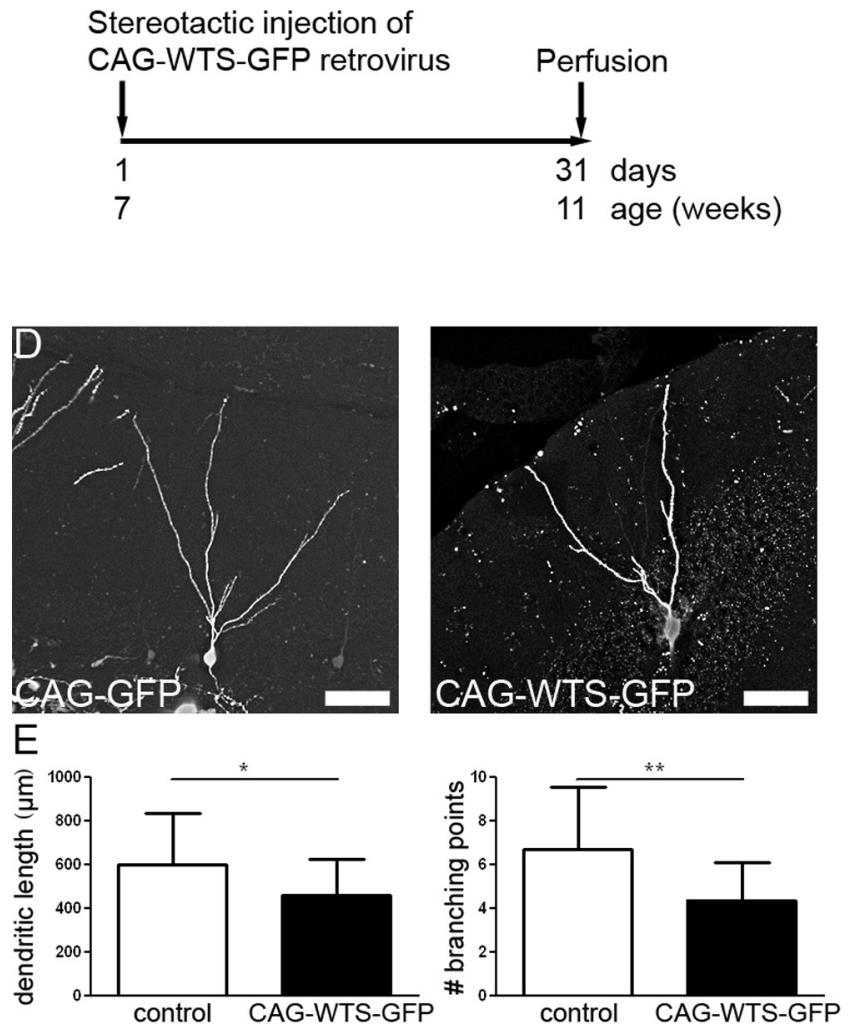
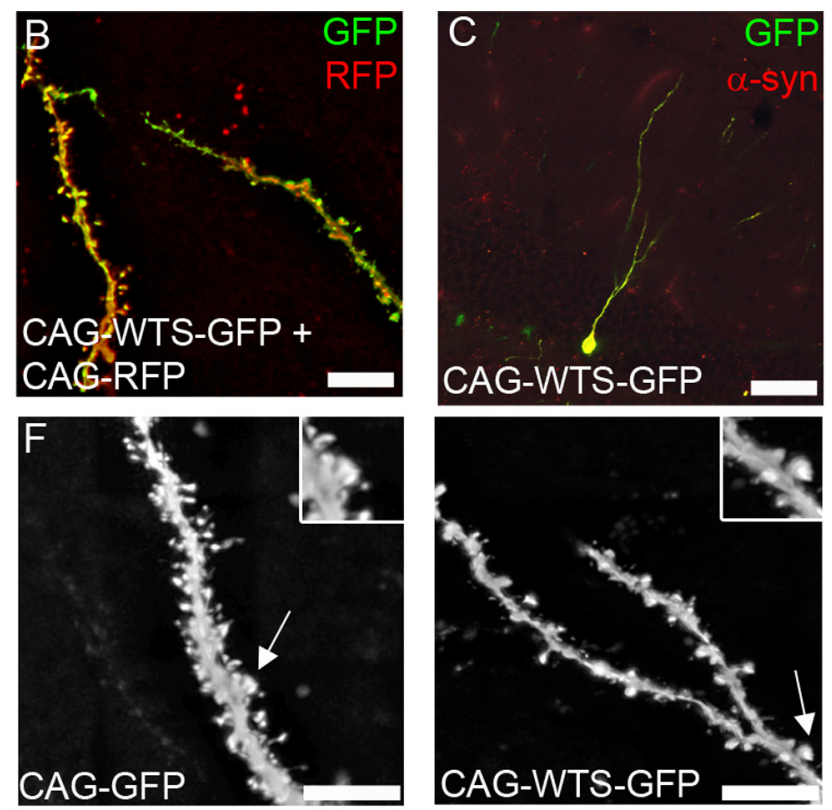

G
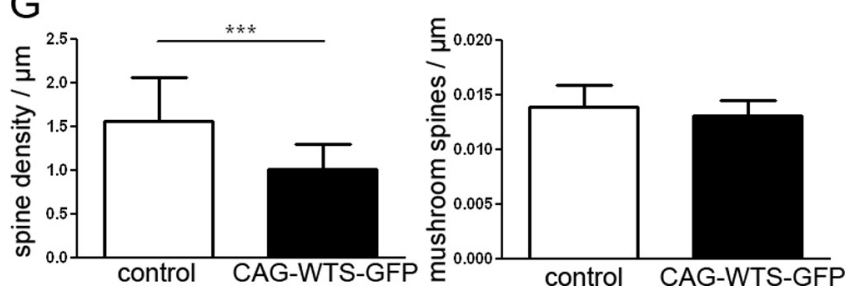

Figure 5. Effects of WTS on dendrite and spine morphology. A, Paradigm: retrovirus overexpressing a human wild-type $\alpha$-Synuclein-GFP fusion protein (CAG-WTS-GFP) or GFP control (CAG-GFP) was injected into the DG of naive mice, and the mice were analyzed 1 month later ( $n=7$ animals per group). $\boldsymbol{B}$, Retrovirus CAG-RFP that overexpresses RFP in infected cells was coinjected with CAG-WTS-GFP. Overlay of GFP (green) and RFP (red) shows that both fluorophores were similarly distributed throughout dendrites and the perikaryon. C, Colabeling for GFP and $\alpha$-synuclein (15G7; $\alpha$-syn) shows colabeling of dendritic trees and perikarya of infected newborn neurons. Representative images of dendrites ( $\boldsymbol{D})$ and spines $(\boldsymbol{F}$; inset shows examples of mushroom spines, arrows). Dendritic length, dendritic branching points $(\boldsymbol{E})$, and spine density $(\boldsymbol{G})$ were decreased in the (AG-WTS-GFP group. No significant differences were detected in the number of mushroom spines (G). Scale bars: $\boldsymbol{B}-\boldsymbol{D}, 50 \mu \mathrm{m} ; \boldsymbol{F}, 10 \mu \mathrm{m} .{ }^{*} p<0.05,{ }^{* *} p<0.01,{ }^{* * *} p<0.001$.

WTS was already expressed at the stem cell stage, as depicted by nuclear colabeling with SOX2 (Fig. 3A). WTS was present throughout the development of the newly generated neurons, as indicated by colabeling with DCX (Fig. 3B), and it was also expressed in $\mathrm{NeuN}^{+}$mature neurons (Fig. 3C). In this PDGF WTS mouse model, $\alpha$-synuclein was expressed from birth through maturation of adult-born neurons. Equally important was that, in the DG, $\alpha$-synuclein accumulated along neurites in close proximity to the newly generated neurons (Fig. 3B).

\section{Compromised dendritic morphology in $\alpha$-synuclein}

Tg animals

To further investigate the impact of $\alpha$-synuclein on neurites and to determine the impact of WTS on dendrite and spine development in newly generated neurons, we injected a retrovirus expressing green fluorescent protein (CAG-GFP) into PDGF WTS mice (paradigm; Fig. $4 A$ ). Four weeks after viral injection, the dendrites of newborn granule cells in NTG mice showed a highly polarized morphology and apical dendritic processes with abundant spines extending into the molecular layer (Fig. 4D). Compared with NTG mice, the dendritic length in PDGF WTS mice was significantly decreased (Fig. $4 B, E$ ); however, no differences in branching points were observed between the groups (Fig. 4C). Given that dendritic growth was perturbed in PDGF WTS mice, we next asked whether spine formation or spine maturation of granule neurons was affected. Surprisingly, we found a significant increase in spine density in the PDGF WTS group (Fig. 4G,H). Tg overexpression of WTS also affected spine maturation in PDGF mice; the formation of mushroom spines was decreased in PDGF WTS mice (Fig. 4I). These results led us to further determine the impact of $\alpha$-synuclein within the newly generated neurons compared with the effect induced by WTS of the surrounding neurogenic niche.

\section{Overexpression of WTS in newly generated neurons leads to} decreased dendritic outgrowth and fewer spines

To investigate the cell-autonomous effects of WTS on newly generated neurons, we used a WTS-GFP fusion protein retrovirus (CAG-WTS-GFP) and a GFP control retrovirus (CAG-GFP). CAG-WTS-GFP and CAG-GFP were injected into the DG of C57BL/6 mice, and the animals were killed 1 month (Fig. 5) or 3 months (data not shown) after the stereotactic injection. We first explored the expression of the CAG-WTS-GFP retrovirus and found it to be similarly distributed throughout the neurites when compared with a coinjected CAG-RFP retrovirus (Fig. 5B). Moreover, CAG-WTS-GFP colabeled with $\alpha$-synuclein (Fig. 5C) and the mossy fiber synaptic marker VAMP2 in the CA3 region, indicating that the retrovirus was distributed throughout the entire newly generated neuron (data not shown). The amount of overexpression, as analyzed by quantitative PCR of the microdissected CAG-WTS-GFP-injected DG (data not shown), was similar to what has been reported in WTS Tg mice (Rockenstein et 
A

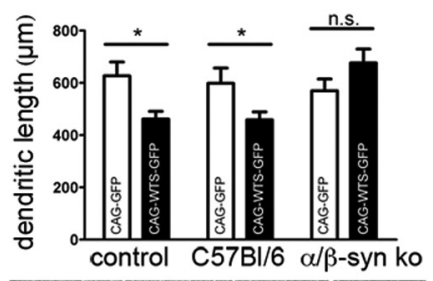

B

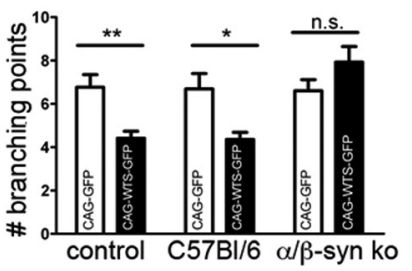

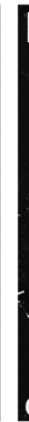

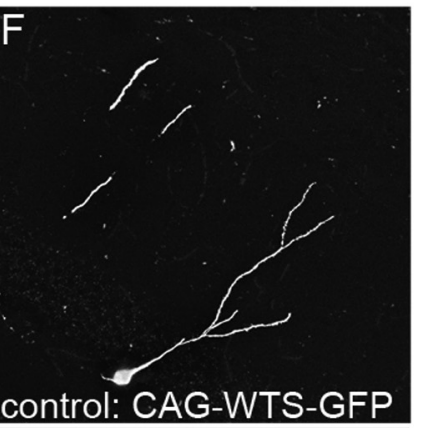

C
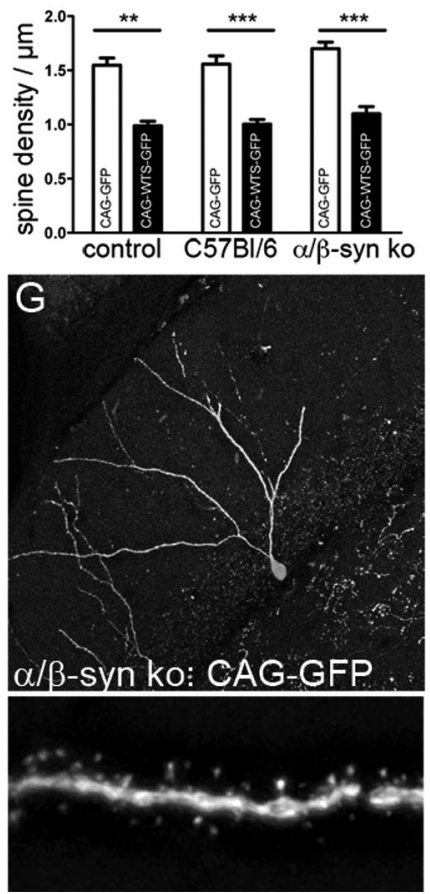

D
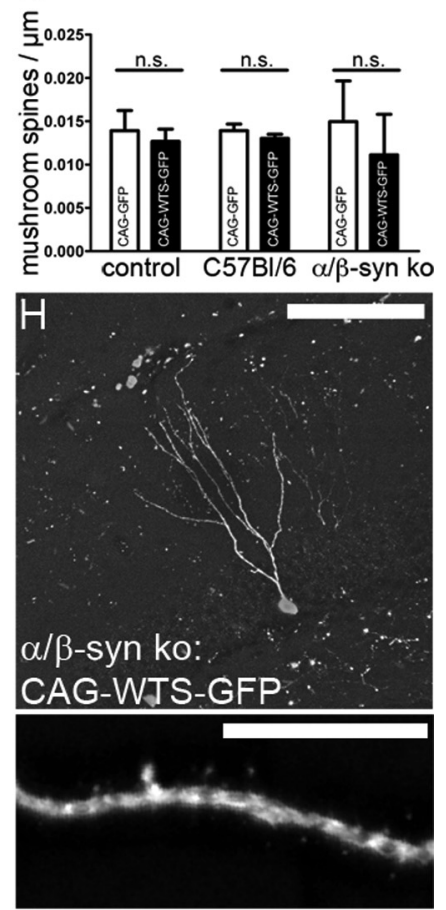

Figure 6. Effects of WTS on dendrite and spine development in $\alpha / \beta$-synuclein knock-out mice $(\alpha / \beta$-syn ko). We asked how endogenous $\alpha$-synuclein levels influenced the effects of cell-autonomous WTS on dendrite and spine morphology. We performed the same injection paradigm as in Figure $5 A$ in $\alpha / \beta$-synuclein knock-out mice and two wild-type groups (controls and (57BL/6, $n=7$ animals per group). In the absence of endogenous $\alpha$-synuclein, overexpressed WTS does not impair dendrite outgrowth (A) or dendritic branching (B). The effects on spines, however, are present despite a deficiency in endogenous $\alpha$-synuclein ( $\boldsymbol{C}$. The mushroom spine subpopulation is unchanged regardless of cell-autonomous $\alpha$-synuclein content ( $\boldsymbol{D})$. Representative micrographs of controls injected with CAG-GFP $(\boldsymbol{E})$ or CAG-WTS-GFP $(\boldsymbol{F})$ and $\alpha / \beta$-synuclein knock-out mice injected with CAG-GFP $(\boldsymbol{G})$ or CAG-WTS-GFP $(\boldsymbol{H})$. Scale bars (in $\boldsymbol{E}-\boldsymbol{H}$ ): top row, 100 $\mu \mathrm{m}$; bottom row, $10 \mu \mathrm{m} .{ }^{*} p<0.05,{ }^{* *} p<0.01,{ }^{* * *} p<0.001$.

al., 2002). One month after retroviral injection, dendritic length, dendritic branching points (Fig. $5 D, E$ ), and spine density (Fig. $5 F, G)$ were significantly decreased by overexpression of WTS selectively in newly generated neurons compared with the control CAG-GFP retrovirus injection alone. These findings indicate that overexpression of WTS within the newly generated neuron significantly impaired dendritic and spine outgrowth. No significant differences were detected in the numbers of mushroom spines (Fig. $5 F, G$ ). The effect of decreased dendritic length and decreased spine density was present even after 3 months (data not shown). Because of this effect of overexpression of WTS in newly generated neurons on dendrites and spines, we next asked whether endogenous mouse $\alpha$-synuclein expression within the DG had an impact on dendrite and spine development.

Effects of endogenous $\alpha$-synuclein on dendrite and spine development

To investigate the impact of hippocampal $\alpha$-synuclein on the development of new neurons, we analyzed the effects on neurite outgrowth of newly generated neurons in the presence or absence of $\alpha$-synuclein. We first asked whether the DG neurite and spine development of newly generated neurons was altered in these $\alpha / \beta$-synuclein knock-out mice, and we labeled the newly generated neurons by injection of retrovirus (CAG-GFP). No differences in dendrite (Fig. $6 A, B, E, G$ ) or spine (Fig. $6 C-E, G$ ) development in newly generated neurons for CAG-GFP were observed in the $\alpha / \beta$-synuclein knock-out mice compared with controls (control and C57BL/6).

Next we investigated the effect of expression of WTS within the newly generated neurons by injecting the CAG-WTS-GFP retrovirus into the DG in an environment not expressing $\alpha / \beta$ synuclein. Control mice (control and C57BL/6) injected with CAG-WTS-GFP showed a significant decrease in dendrite length and branching points (Fig. $6 A, B, F$ ). Surprisingly, overexpression of WTS in newly generated DG neurons in the $\alpha / \beta$ synuclein knock-outs did not show a reduction in dendrite length and branching points (Fig. $6 A, B, H$ ), but the values of the WTSCAG-GFP group for dendrite length and branching points were similar to those of the CAG-GFP-injected controls (Fig. $6 A, B, H)$. After WTS-CAG-GFP injection, spine density was equally impaired in $\alpha / \beta$-synuclein knock-outs and littermate controls (Fig. 6C), but mushroom spine numbers were not altered under any of the conditions analyzed (Fig. 6D).

\section{Rolipram reverses WTS-induced spine alterations}

Because these results revealed that modulation of $\alpha$-synuclein had a strong impact on adult neurogenesis and dendrite and spine development, we sought to determine whether we could reverse the deficit. We tested a pharmacological restoration of the WTS-induced impairment in dendrite and spine development by administration of rolipram. This selective cAMP-specific phosphodiesterase 4 inhibitor increases cAMP and, consecutively, phosphorylation of CREB (MacKenzie and Houslay, 2000). We treated $\mathrm{C} 57 \mathrm{BL} / 6$ mice daily with rolipram for a total of $36 \mathrm{~d}$, starting $5 \mathrm{~d}$ before retroviral labeling (CAG-GFP and CAGWTS-GFP) of newly generated neurons, and we continued this treatment until perfusion (Fig. 7A). In the control CAG-GFP group, rolipram increased the number of mushroom spines (Fig. $7 E$ ). Dendritic length, dendritic branching, and spine density were not statistically different between treated and control 
A

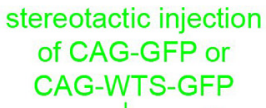

B

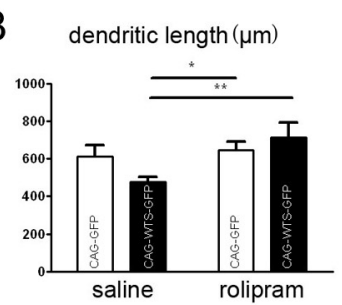

D

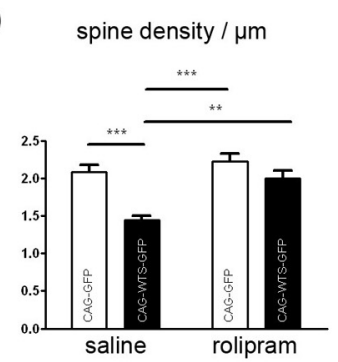

\section{C}

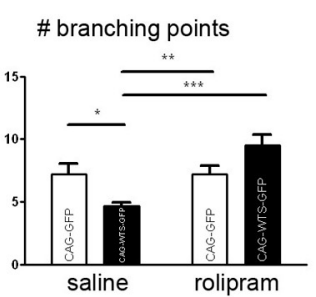

E
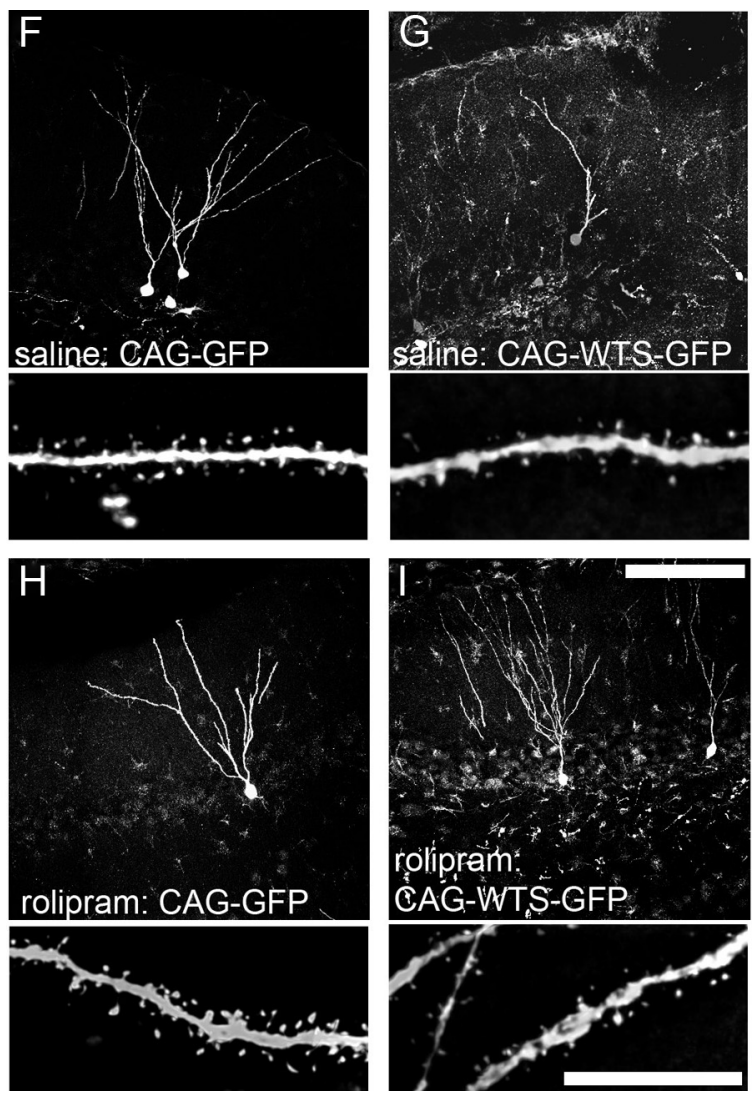

Figure 7. Partial reversal of WTS-induced spine alterations by CREB-activator rolipram. Daily treatment with rolipram $(1.25 \mathrm{mg} / \mathrm{kg})$ was started $5 \mathrm{~d}$ before retroviral labeling of newborn neurons and continued until perfusion ( $\boldsymbol{A}$ ). Dendritic length was significantly different between newborn neurons overexpressing CAG-WTS-GFP in saline versus rolipram-treated animals ( $\boldsymbol{B})$. Likewise, impairments in dendritic branching and spine density were not present in rolipram-treated animals injected with CAG-WTS-GFP (C, D). No significant effect of rolipram treatment on mushroom spines was observed in the CAG-WTS-GFP group $(\boldsymbol{E})$. $\boldsymbol{F}$ - $\boldsymbol{I}$, Representative images from saline-treated animals injected with CAG-GFP $(\boldsymbol{F})$ or $(A G-W T S-G F P(\boldsymbol{G})$ and from rolipram-treated animals injected with CAG-GFP $(\boldsymbol{H})$ or CAG-WTS-GFP $(\boldsymbol{I})$. Scale bars (in $\boldsymbol{F}-\boldsymbol{I})$ : top row (dendrite overviews), $100 \mu \mathrm{m}$; bottom row (spine magnifications), $10 \mu \mathrm{m} .{ }^{*} p<0.05,{ }^{* *} p<0.01$, ${ }^{* * *} p<0.001$.

groups (Fig. $7 B-D)$. In addition, we confirmed an increase in adult neurogenesis in the rolipram-injected animals, as described previously (data not shown).

The dendritic length of newly generated neurons overexpressing CAG-WTS-GFP was increased by rolipram treatment compared with the saline-treated CAG-WTS-GFP-injected animals (Fig. $7 B$ ). Rolipram treatment increased dendritic branching and spine density in CAG-WTS-GFP-injected animals (Fig. 7C,D). It has to be noted that, in saline-treated animals, WTS led to a trend of dendrite length reduction that, in contrast to the results above, was not significant.

\section{Discussion}

This study provides evidence for the involvement of $\alpha$-synuclein in regulating adult hippocampal neurogenesis. We showed that knock-out of $\alpha / \beta$-synuclein increased neuronal differentiation, whereas overexpression of WTS within the newly generated neuron in PDGF WTS mice and retroviral CAG-WTS-GFP overexpression had a negative impact on adult neurogenesis and dendrite development. The overexpression of WTS within the hippocampal niche (e.g., PDGF WTS) also had an impact on spine development. Interestingly, the interaction between WTS expression within the newly generated neuron and expression of mouse endogenous $\alpha$-synuclein around the newly generated neuron also played an important role in dendrite development in the newly generated neuron, as summarized in Figure 8.

The increased number of $\alpha$-synuclein ${ }^{+}$cells in the human DG in $\mathrm{LBD}$ patients and the decreased progenitor cell population is sugges- tive of a decrease in adult neurogenesis in LBD. We provide evidence here that $\alpha$-synuclein might contribute to decreased numbers of progenitors in synucleinopathies, which is in line with a recent human study in LBD brains (Johnson et al., 2011).

To further clarify the impact of $\alpha$-synuclein on the DG, we investigated adult neurogenesis in the absence of $\alpha$-synuclein. Because $\alpha$-synuclein and $\beta$-synuclein are both widely colocalized in presynaptic nerve terminals and highly coexpressed, indicating redundancy ( $\mathrm{Li}$ et al., 2002), we used double $\alpha / \beta$-synuclein knock-out mice (Chandra et al., 2004). The downregulation of $\alpha / \beta$-synuclein resulted in an increased percentage of surviving new neurons, which was unlikely to be background related, because the number of new neurons was even higher than pure C57BL/6 mice, which are known to have a high level of neurogenesis (Kempermann et al., 2006). Our group had shown previously that overexpression of $\alpha$-synuclein decreased hippocampal neurogenesis (Winner et al., 2004; Nuber et al., 2008). The finding of increased neurogenesis in $\alpha / \beta$-knock-outs further indicates a modulatory role for $\alpha$ - and/or $\beta$-synuclein in adult neurogenesis. Therefore, we pursued further the study of cellautonomous versus non-autonomous interactions of $\alpha$-synuclein in newly generated neurons in the DG.

$\alpha$-Synuclein was expressed in the hippocampus within new neurons endogenously in controls and in PDGF WTS mice. The expression of endogenous $\alpha$-synuclein was similarly shown by in situ hybridizations in the Allen Brain Atlas (mouse brain: SNCA, riboprobe identification number RP_Baylor_103043, coronal; 
A physiological

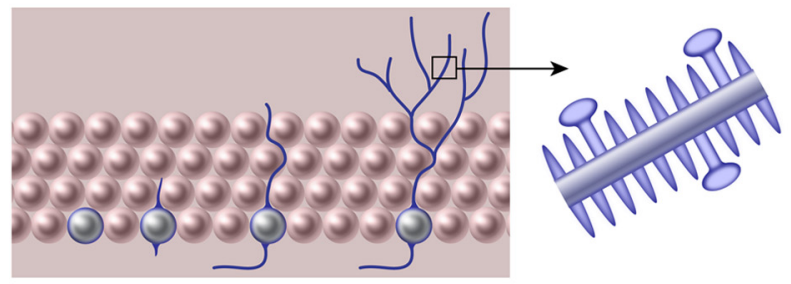

\section{CAG-WTS-GFP retrovirus}
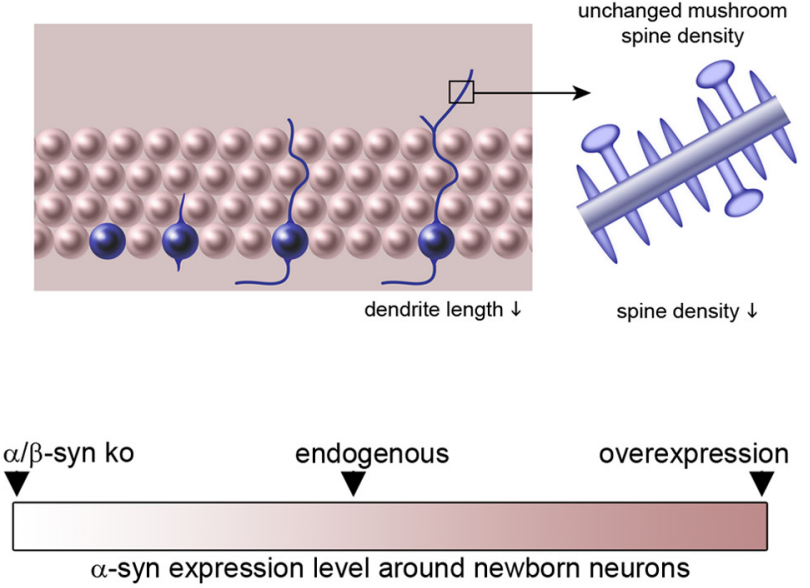

\section{B transgenic PDGF WTS}

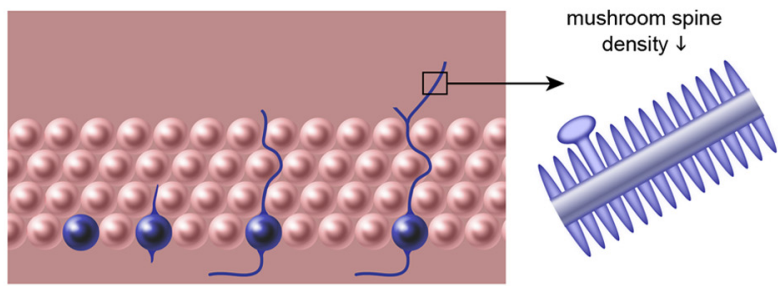

dendrite length $\downarrow$

spine density $\uparrow$

D $\alpha / \beta$-syn ko + CAG-WTS-GFP

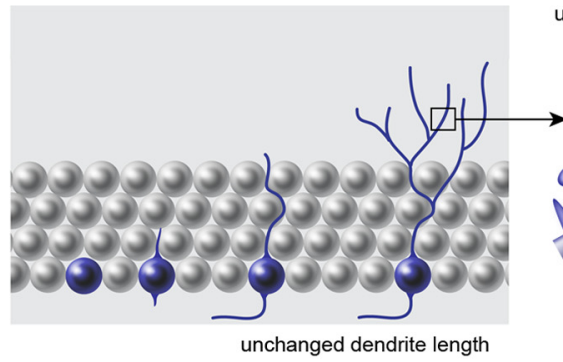

unchanged mushroom spine density

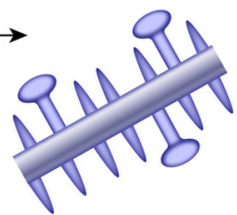

spine density $\downarrow$

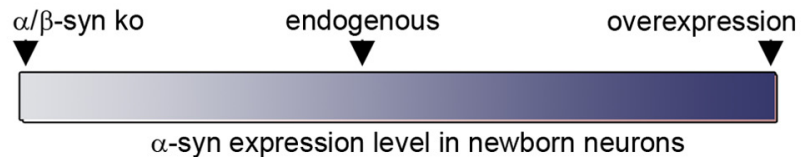

Figure 8. Model of effects of human WTS and mouse endogenous $\alpha$-synuclein. Model of the physiological development of a newborn neuron in the adult DG $(A)$. A newly generated neuron integrating into the $D G$ is shown on the left of all images; the right depicts a higher-magnified inset of a dendrite showing spines and the larger mushroom spines $(\boldsymbol{A}-\boldsymbol{D})$. $\boldsymbol{B}-\boldsymbol{D}$, Models showing the impact of WTS on dendrite and spine development. $\boldsymbol{B}$, PDGFWTS mice; $\boldsymbol{C}$, retroviral overexpression of WTS using a CAG-WTS-GFP construct; $\boldsymbol{D}$, retroviral overexpression of WTS on a $\alpha / \beta$-synuclein knock-out background $(\alpha / \beta$-syn ko). Cell-specific overexpression of WTS results in decreased dendrite length and spine density $(\boldsymbol{B}, \boldsymbol{C})$, whereas nonspecific overexpression ( $\boldsymbol{B})$ leads to a decrease in mushroom spines, as indicated in the purple panels showing an example of magnification of the spines.

http://www.brain-map.org/). Expression of transgenic $\alpha$-synuclein in PDGF WTS mice (line D; Rockenstein et al., 2002) and its distribution in the hippocampus were also comparable. By analyzing neurite outgrowth after injection of a GFP retrovirus into the PDGF WTS mice and controls, we showed that dendrite outgrowth of newly generated neurons was significantly impaired in the PDGF WTS mice. To further test the impact of $\alpha$-synuclein in newly generated neurons, we investigated selective overexpression of WTS in newly generated neurons. Again, we observed a decrease in dendritic length, and branching was also impaired.

To distinguish the impact of endogenous and overexpression of $\alpha$-synuclein in newly generated neurons, we used an $\alpha-/ \beta$-synuclein knock-out model. In the absence of endogenous mouse $\alpha$-/ $\beta$-synuclein, dendrite development of CAGGFP-labeled newly generated neurons was not altered. However, the previously observed effect of dendrite length reduction after overexpression of $\alpha$-synuclein in newly generated neurons (CAG-WTS-GFP) was no longer present in the $\alpha / \beta$-synuclein knock-out mice. These experiments showed that cell-autonomous overexpression of WTS induced a reduction in dendrite length. This reduced dendrite length could be modulated by changes in the concentration of endogenous $\alpha$-synuclein levels even if they were only detected at low levels.

Reductions in dendrite numbers, dendrite length and branching, and spine density have been reported in striatal medium spiny neurons in PD patients (McNeill et al., 1988; ZajaMilatovic et al., 2005) and in the substantia nigra (Patt et al., 1991). In addition, in vitro studies reported a negative impact of $\alpha$-synuclein on neurite outgrowth and synaptic integration (Takenouchi et al., 2001; Crews et al., 2008).

The postsynaptic effects of $\alpha$-synuclein on dendrites and spines are less well understood. The increase in spine density observed in the PDGF WTS mice might be indicative of a compensatory effect in early presynaptic and postsynaptic pathology, in which pruning is reduced as a result of dendritic atrophy and reduced connectivity (for review, see Fiala et al., 2002). When WTS levels were selectively increased in the newly generated neurons but not increased in their surroundings, spine numbers were decreased. Similar observations were made in $\alpha / \beta$-synuclein knock-out mice.

Reductions in mushroom spines, indicating a lack of maturation, have been observed in PDGF WTS mice. Because increased expression of $\alpha$-synuclein reduces neurotransmitter release as well as synaptic vesicle reclustering (Nemani et al., 2010), we speculate that the overexpression of $\alpha$-synuclein hinders normal levels of presynaptic activity. These findings further strengthen the impact of the presynaptic compartment of spine maturation and size in synucleinopathies.

Rolipram restored WTS-induced morphological dendrite alterations in dendritic length, dendritic branching points, and spine density. Rolipram itself is a specific phosphodiesterase-4 inhibitor leading to increased levels of cAMP, which activates PKA and CREB (Silva et al., 1998). Dominant-negative CREB overexpression prevents the proliferative effect on neural progenitor cells (Nakagawa et al., 2002). The impact of rolipram in the hippocampus may also involve the glucocorticoid receptor 
(GR), because the effect of rolipram on adult neurogenesis is prevented by a GR antagonist (Anacker et al., 2011).

In $\mathrm{PD}$ postmortem brains, the large amount of presynaptic $\alpha$-synuclein aggregates has a major pathological impact on dendritic spine maintenance. Decreases in the postsynaptic scaffold protein postsynaptic density-95 and the f-actin-binding postsynaptic protein drebrin have been reported in LBD, indicating the impact of synaptic dysfunction in synucleinopathies (Kramer and Schulz-Schaeffer, 2007). These findings have parallels with other neurodegenerative diseases, e.g., Alzheimer's disease, in which a correlation between amyloid oligomer amount, dendritic spines, and memory deficit was shown (Terry et al., 1991; Walsh et al., 2002). It is intriguing that similar connections between protein aggregation, synaptic connectivity, and memory function might be present in synucleinopathies. Our results reveal a negative impact of $\alpha$-synuclein on newly generated neurons, in particular on their dendrite outgrowth and spine development. These deleterious effects of $\alpha$-synuclein may underline some components of the cognitive impairments reported in synucleinopathies.

\section{References}

Altman J, Das GD (1965) Autoradiographic and histological evidence of postnatal hippocampal neurogenesis in rats. J Comp Neurol 124:319335. CrossRef Medline

Anacker C, Zunszain PA, Carvalho LA, Pariante CM (2011) The glucocorticoid receptor: pivot of depression and of antidepressant treatment? Psychoneuroendocrinology 36:415-425. CrossRef Medline

Apostolova LG, Beyer M, Green AE, Hwang KS, Morra JH, Chou YY, Avedissian C, Aarsland D, Janvin CC, Larsen JP, Cummings JL, Thompson PM (2010) Hippocampal, caudate, and ventricular changes in Parkinson's disease with and without dementia. Mov Disord 25:687-695. CrossRef Medline

Baba M, Nakajo S, Tu PH, Tomita T, Nakaya K, Lee VM, Trojanowski JQ, Iwatsubo T (1998) Aggregation of alpha-synuclein in Lewy bodies of sporadic Parkinson's disease and dementia with Lewy bodies. Am J Pathol 152:879-884. Medline

Braak H, Del Tredici K, Rüb U, de Vos RA, Jansen Steur EN, Braak E (2003) Staging of brain pathology related to sporadic Parkinson's disease. Neurobiol Aging 24:197-211. CrossRef Medline

Camicioli R, Moore MM, Kinney A, Corbridge E, Glassberg K, Kaye JA (2003) Parkinson's disease is associated with hippocampal atrophy. Mov Disord 18:784-790. CrossRef Medline

Carlesimo GA, Piras F, Assogna F, Pontieri FE, Caltagirone C, Spalletta G (2012) Hippocampal abnormalities and memory deficits in Parkinson disease: a multimodal imaging study. Neurology 78:1939-1945. CrossRef Medline

Chandra S, Fornai F, Kwon HB, Yazdani U, Atasoy D, Liu X, Hammer RE, Battaglia G, German DC, Castillo PE, Südhof TC (2004) Doubleknockout mice for alpha- and beta-synucleins: effect on synaptic functions. Proc Natl Acad Sci U S A 101:14966-14971. CrossRef Medline

Clelland CD, Choi M, Romberg C, Clemenson GD Jr, Fragniere A, Tyers P, Jessberger S, Saksida LM, Barker RA, Gage FH, Bussey TJ (2009) A functional role for adult hippocampal neurogenesis in spatial pattern separation. Science 325:210-213. CrossRef Medline

Crews L, Mizuno H, Desplats P, Rockenstein E, Adame A, Patrick C, Winner B, Winkler J, Masliah E (2008) $\alpha$-Synuclein alters Notch-1 expression and neurogenesis in mouse embryonic stem cells and in the hippocampus of transgenic mice. J Neurosci 28:4250-4260. CrossRef Medline

Eriksson PS, Perfilieva E, Björk-Eriksson T, Alborn AM, Nordborg C, Peterson DA, Gage FH (1998) Neurogenesis in the adult human hippocampus. Nat Med 4:1313-1317. CrossRef Medline

Fiala JC, Spacek J, Harris KM (2002) Dendritic spine pathology: cause or consequence of neurological disorders? Brain Res Brain Res Rev 39:2954. CrossRef Medline

Gundersen HJ, Bagger P, Bendtsen TF, Evans SM, Korbo L, Marcussen N, Møller A, Nielsen K, Nyengaard JR, Pakkenberg B, Sorensen FB, Vesterby A, West MJ (1988) The new stereological tools: disector, fractionator, nucleator and point sampled intercepts and their use in pathological research and diagnosis. APMIS 96:857-881. CrossRef Medline
Höglinger GU, Rizk P, Muriel MP, Duyckaerts C, Oertel WH, Caille I, Hirsch EC (2004) Dopamine depletion impairs precursor cell proliferation in Parkinson disease. Nat Neurosci 7:726-735. CrossRef Medline

Johnson M, Ekonomou A, Hobbs C, Ballard CG, Perry RH, Perry EK (2011) Neurogenic marker abnormalities in the hippocampus in dementia with Lewy bodies. Hippocampus 21:1126-1136. CrossRef Medline

Kempermann G, Chesler EJ, Lu L, Williams RW, Gage FH (2006) Natural variation and genetic covariance in adult hippocampal neurogenesis. Proc Natl Acad Sci U S A 103:780-785. CrossRef Medline

Knoth R, Singec I, Ditter M, Pantazis G, Capetian P, Meyer RP, Horvat V, Volk B, Kempermann G (2010) Murine features of neurogenesis in the human hippocampus across the lifespan from 0 to 100 years. PLoS One 5:e8809. CrossRef Medline

Kramer ML, Schulz-Schaeffer WJ (2007) Presynaptic alpha-synuclein aggregates, not Lewy bodies, cause neurodegeneration in dementia with Lewy bodies. J Neurosci 27:1405-1410. CrossRef Medline

Kuhn HG, Dickinson-Anson H, Gage FH (1996) Neurogenesis in the dentate gyrus of the adult rat: age-related decrease of neuronal progenitor proliferation. J Neurosci 16:2027-2033. Medline

Li JY, Henning Jensen P, Dahlström A (2002) Differential localization of alpha-, beta- and gamma-synucleins in the rat CNS. Neuroscience 113: 463-478. CrossRef Medline

MacKenzie SJ, Houslay MD (2000) Action of rolipram on specific PDE4 cAMP phosphodiesterase isoforms and on the phosphorylation of cAMPresponse-element-binding protein (CREB) and p38 mitogen-activated protein (MAP) kinase in U937 monocytic cells. Biochem J 347:571-578. CrossRef Medline

Masliah E, Rockenstein E, Veinbergs I, Mallory M, Hashimoto M, Takeda A, Sagara Y, Sisk A, Mucke L (2000) Dopaminergic loss and inclusion body formation in alpha-synuclein mice: implications for neurodegenerative disorders. Science 287:1265-1269. CrossRef Medline

McKeith IG, Dickson DW, Lowe J, Emre M, O’Brien JT, Feldman H, Cummings J, Duda JE, Lippa C, Perry EK, Aarsland D, Arai H, Ballard CG, Boeve B, Burn DJ, Costa D, Del Ser T, Dubois B, Galasko D, Gauthier S, et al. (2005) Diagnosis and management of dementia with Lewy bodies: third report of the DLB Consortium. Neurology 65:1863-1872. CrossRef Medline

McNeill TH, Brown SA, Rafols JA, Shoulson I (1988) Atrophy of medium spiny I striatal dendrites in advanced Parkinson's disease. Brain Res 455: 148-152. CrossRef Medline

Molano J, Boeve B, Ferman T, Smith G, Parisi J, Dickson D, Knopman D, Graff-Radford N, Geda Y, Lucas J, Kantarci K, Shiung M, Jack C, Silber M, Pankratz VS, Petersen R (2010) Mild cognitive impairment associated with limbic and neocortical Lewy body disease: a clinicopathological study. Brain 133:540-556. CrossRef Medline

Nakagawa S, Kim JE, Lee R, Malberg JE, Chen J, Steffen C, Zhang YJ, Nestler EJ, Duman RS (2002) Regulation of neurogenesis in adult mouse hippocampus by cAMP and the cAMP response element-binding protein. J Neurosci 22:3673-3682. Medline

Nemani VM, Lu W, Berge V, Nakamura K, Onoa B, Lee MK, Chaudhry FA, Nicoll RA, Edwards RH (2010) Increased expression of alpha-synuclein reduces neurotransmitter release by inhibiting synaptic vesicle reclustering after endocytosis. Neuron 65:66-79. CrossRef Medline

Nuber S, Petrasch-Parwez E, Winner B, Winkler J, von Hörsten S, Schmidt T, Boy J, Kuhn M, Nguyen HP, Teismann P, Schulz JB, Neumann M, Pichler BJ, Reischl G, Holzmann C, Schmitt I, Bornemann A, Kuhn W, Zimmermann F, Servadio A, Riess O (2008) Neurodegeneration and motor dysfunction in a conditional model of Parkinson's disease. J Neurosci 28: 2471-2484. CrossRef Medline

Patt S, Gertz HJ, Gerhard L, Cervos-Navarro J (1991) Pathological changes in dendrites of substantia nigra neurons in Parkinson's disease: a Golgi study. Histol Histopathol 6:373-380. Medline

Pavese N, Metta V, Bose SK, Chaudhuri KR, Brooks DJ (2010) Fatigue in Parkinson's disease is linked to striatal and limbic serotonergic dysfunction. Brain 133:3434-3443. CrossRef Medline

Politis M, Wu K, Loane C, Turkheimer FE, Molloy S, Brooks DJ, Piccini P (2010) Depressive symptoms in PD correlate with higher 5-HTT binding in raphe and limbic structures. Neurology 75:1920-1927. CrossRef Medline

Possin KL, Filoteo JV, Song DD, Salmon DP (2008) Spatial and object working memory deficits in Parkinson's disease are due to impairment in 
different underlying processes. Neuropsychology 22:585-595. CrossRef Medline

Rockenstein E, Mallory M, Hashimoto M, Song D, Shults CW, Lang I, Masliah E (2002) Differential neuropathological alterations in transgenic mice expressing alpha-synuclein from the platelet-derived growth factor and Thy-1 promoters. J Neurosci Res 68:568-578. CrossRef Medline

Silva AJ, Kogan JH, Frankland PW, Kida S (1998) CREB and memory. Annu Rev Neurosci 21:127-148. CrossRef Medline

Spillantini MG, Schmidt ML, Lee VM, Trojanowski JQ, Jakes R, Goedert M (1997) Alpha-synuclein in Lewy bodies. Nature 388:839-840. CrossRef Medline

Takenouchi T, Hashimoto M, Hsu LJ, Mackowski B, Rockenstein E, Mallory M, Masliah E (2001) Reduced neuritic outgrowth and cell adhesion in neuronal cells transfected with human alpha-synuclein. Mol Cell Neurosci 17:141-150. CrossRef Medline

Terry RD, Masliah E, Salmon DP, Butters N, DeTeresa R, Hill R, Hansen LA, Katzman R (1991) Physical basis of cognitive alterations in Alzheimer's disease: synapse loss is the major correlate of cognitive impairment. Ann Neurol 30:572-580. CrossRef Medline

Walsh DM, Klyubin I, Fadeeva JV, Cullen WK, Anwyl R, Wolfe MS, Rowan MJ, Selkoe DJ (2002) Naturally secreted oligomers of amyloid beta pro- tein potently inhibit hippocampal long-term potentiation in vivo. Nature 416:535-539. CrossRef Medline

Weintraub D, Doshi J, Koka D, Davatzikos C, Siderowf AD, Duda JE, Wolk DA, Moberg PJ, Xie SX, Clark CM (2011) Neurodegeneration across stages of cognitive decline in Parkinson disease. Arch Neurol 68:15621568. CrossRef Medline

Williams RW, Rakic P (1988) Three-dimensional counting: an accurate and direct method to estimate numbers of cells in sectioned material. J Comp Neurol 278:344-352. CrossRef Medline

Winner B, Lie DC, Rockenstein E, Aigner R, Aigner L, Masliah E, Kuhn HG, Winkler J (2004) Human wild-type alpha-synuclein impairs neurogenesis. J Neuropathol Exp Neurol 63:1155-1166. Medline

Winner B, Kohl Z, Gage FH (2011) Neurodegenerative disease and adult neurogenesis. Eur J Neurosci 33:1139-1151. CrossRef Medline

Zaja-Milatovic S, Milatovic D, Schantz AM, Zhang J, Montine KS, Samii A, Deutch AY, Montine TJ (2005) Dendritic degeneration in neostriatal medium spiny neurons in Parkinson disease. Neurology 64:545-547. CrossRef Medline

Zhao C, Teng EM, Summers RG Jr, Ming GL, Gage FH (2006) Distinct morphological stages of dentate granule neuron maturation in the adult mouse hippocampus. J Neurosci 26:3-11. CrossRef Medline 